\title{
Application of Infrared Heating for Roasting Nuts
}

\author{
Hadi Bagheri (D) \\ Faculty of Food Science \& Technology, Gorgan University of Agricultural Sciences and Natural Resources, Gorgan, Iran \\ Correspondence should be addressed to Hadi Bagheri; bagherihadi51@yahoo.com
}

Received 3 June 2020; Revised 5 July 2020; Accepted 9 July 2020; Published 4 August 2020

Academic Editor: Francisca Hernández

Copyright (c) 2020 Hadi Bagheri. This is an open access article distributed under the Creative Commons Attribution License, which permits unrestricted use, distribution, and reproduction in any medium, provided the original work is properly cited.

Roasting is a key process in production of nuts. Improving the flavor and crispiness of texture in nuts is considered as a purpose of roasting, which increases the overall acceptance of the product. This review aims to introduce the infrared method as a new technique of roasting and evaluate the quality characteristics of some nuts after infrared roasting. Usually, the traditional roasting methods are time-consuming with high energy consumption and low production efficiency. One of the best ways to decrease roasting time and energy consumption is to provide heat by infrared (IR) radiation. However, the low penetration power of infrared radiation is one of the limitations of this method. The combination of infrared with other thermal methods can overcome this limitation. Studies have been done on roasting of nuts and other foods by different IR roasting methods such as IR, IR-hot air, and IR-microwave roasting methods. This paper reviews the effect of different IR roasting methods on the quality characteristics of roasted pistachio, peanut, hazelnut, almond, sunflower, soybean, and other food products. IR heating has been applied successfully to the roasting of some nuts. The use of infrared roasting has several advantages in comparison with traditional convective roasting methods. According to the results of most of these studies, the combination of infrared with other thermal methods to roast nuts has distinctly improved the potential of the technology as compared to the IR roasting alone.

\section{Introduction}

Roasting is known as a thermal time-temperature-dependent process at high temperatures $\left(>150^{\circ} \mathrm{C}\right)$. It leads to the production of high value-added products with better flavor and crispier texture [1]. Along with salting and drying, roasting is one of the main unit operations used for processing nuts (Figure 1). This operation is aimed at improving appeal and taste to consumers. Roasting through physicochemical reactions (nonenzymatic browning as Millard reaction) and heat and mass transfer leads to an improvement of color, flavor, and textural of nuts [1].

1.1. Purpose of Roasting. Improving taste, flavor, color, and textural is the main objective of roasting. Furthermore, removing unwanted volatile acids; lowing water content; destroying troublesome microbes, toxicant material, and food pollution; and inactivating detrimental enzymes (enzymes that cause nutrient loss) are other purposes of roasting [2]. Moreover, some compounds such as fatty acids, peptides, free amino acids, and vitamins are altered during the roasting process $[3,4]$. Starch gelatinization and protein denaturation are the most critical changes in grains and legumes during the roasting process [5].

1.2. Conventional Roasting Methods. Commonly hot air, hot pan, and oven are basic ways for roasting nuts. Usually, these roasting methods are time-consuming and have high energy consumption and low production efficiency [6]. Hot air roasting is one of the simplest convective methods of heating with low operating costs and is commonly applied for roasting of nuts. However, this system requires high thermal energy and extended time for roasting and results in adverse changes in the final product, mainly due to the Maillard reaction $[4,7]$.

In conventional roasting methods, the exterior surface of the nut is overroasted, while the center of the nut is not perfectly roasted. This can cause nonuniform roasting, burned surfaces, and development of unpleasant aroma and flavor and bitter burned taste. To overcome nonuniform 


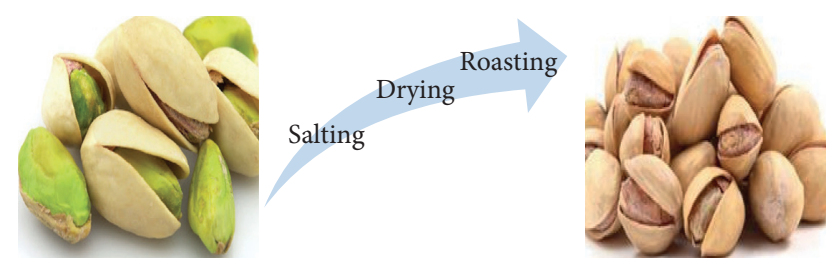

FIgURE 1: Processing steps and preparation of roasted nuts (unit operations).

roasting and its drawbacks, novel methods such as infrared heating have the potential to improve roasting behavior. Infrared radiation can significantly reduce the roasting time of nuts by roasting the thin layer of substance [8].

Unfortunately, very few studies have been conducted on the use of infrared for roasting nuts, and there are no review articles about infrared roasting. Thus the main objectives of this review were (1) to introduce the infrared heating as a new method of roasting and (2) to evaluate the quality characteristics of some nuts after IR roasting.

1.3. Infrared Radiation. Infrared (IR) roasting has gained popularity as a promising alternative technique for roasting of nuts and seeds because of its advantages like lower energy cost, high heat efficiency, compact size of the equipment, and high diffusion coefficient [9]. Infrared is energy in the range of the electromagnetic spectrum between microwaves and visible light. IR has frequencies from about $30 \mathrm{THz}$ up to about $430 \mathrm{THz}$ and wavelengths of about 0.75 to $1000 \mu \mathrm{m}$ (Figure 2) subdivided into short-wave IR $(0.75-2 \mu \mathrm{m}$ near infrared), medium-wave IR $(2-4 \mu \mathrm{m}$ mid-infrared), and long-wave IR (4-1000 $\mu \mathrm{m}$ far infrared) $[10,11]$. For processes such as drying, roasting, thawing, baking, pasteurization, and cooking, FIR heat can be used, which has a wavelength between 4 and $1000 \mu \mathrm{m}$ [11].

Using IR heating in roasting is newly of special interest due to the development in radiator construction. Effectiveness is the capability of producing a desired result or the ability to produce desired output. IR heating effectiveness is between $80 \%$ and $90 \%$, the emitted radiation is in narrow wavelength range, and they are miniaturized [12].
1.4. Mode of Heating. IR roasting methods have some basic differences in the mode of heating. In hot air roasting, heat energy generated is transferred to the surface of the material by convection which is then conveyed internally by thermal conduction [13]. In IR roasting, the material is exposed to IR radiation which interacts, penetrates, and transfers thermal energy in the form of electromagnetic waves throughout the material. Hence, heating occurs uniformly throughout the food mass in IR roasting [9].

1.5. Advantages and Disadvantages of Infrared Rays. Continuous and uniform distribution of IR energy and direct transfer of radiation from IR emitters to the product surface without the need for any physical environment cause the production of high-quality food with minimal energy consumption. These are some advantages of infrared heating. Also, high degree of process control, an alternate source of energy, possibility of selective heating close-packed configurations and different types of IR emitters, and environment-friendly energy are other advantages of this method (Figure 3) $[13,14]$. The low penetration power of infrared radiation is one of the limitations of this method. Also, prolonged exposure may cause fracturing in biological materials, and insensitivity to the reflective properties of the coating is another limitation of this technology $[15,16]$.

In recent years, the use of infrared for roasting nuts and beans has attracted the attention of researchers and has become particularly popular [17]. Due to advances in the construction of emitters, the use of IR heating for roasting nuts has grown significantly [18]. Roasting of nuts and other food products is done with IR roasters (Table 1). As shown in Table 1, the different types of nuts and other foods roasted by infrared heat and acceptable results have been reported by researchers.

1.6. Heat Transfer during Infrared Roasting. IR heating has demonstrated the advantage of efficient heat transfer to food products with reduced processing time and energy costs. Infrared (IR) radiation is energy in the form of electromagnetic wave and is more rapid in heat transfer than convection and conduction mechanisms.

The infrared radiation heat transfer rate (1) between the infrared emitter and the sample surface, $q_{0}$, is given by [33]

$$
q_{0}=\frac{\sigma\left(T_{\mathrm{IF}}^{4}-T_{\mathrm{S}}^{4}\right)}{\left(\left(1-\varepsilon_{\mathrm{IF}} / A_{\mathrm{IF}} \varepsilon_{\mathrm{IF}}\right)+\left(A_{\mathrm{IF}} F_{\mathrm{s}, \mathrm{IF}}+\left(1 /\left(1 / A_{\mathrm{IF}} F_{\mathrm{IF}, \mathrm{W}}+\left(1 / A_{\mathrm{S}} F_{\mathrm{W}, \mathrm{S}}\right)\right)\right)\right)^{-1}+\left(1-\varepsilon_{\mathrm{s}} / A_{\mathrm{s}} \varepsilon_{\mathrm{s}}\right)\right)} .
$$

Therefore, radiation heat transfer flux (2) between the emitter and the sample is given by [34]

$$
q_{f}=\frac{q_{0}}{A_{0}}
$$

where $\varepsilon_{\mathrm{IF}}$ is the infrared emitter emissivity, $\varepsilon_{\mathrm{s}}$ is the emissivity of the sample, $T_{\mathrm{IF}}$ is the temperature of the emitter; $T_{\mathrm{s}}$ is the temperature of the sample surface; $\sigma$ is Stefan-Boltzmann radiation constant $\left(5.67 \times 10-8 \mathrm{~W} \mathrm{~m}^{-2} \mathrm{~K}^{-4}\right)$, $A_{\mathrm{s}}$ is the surface area of the sample, and $A_{\mathrm{IF}}$ is the area of the infrared emitter.

$F_{\mathrm{S}, \mathrm{IF}}$ is the fraction of energy between the IR emitter surface and sample surface, $\mathrm{F}_{\mathrm{IF}, \mathrm{w}}$ is the fraction of energy between the emitter surface and the wall surface, and $F_{\mathrm{w}, \mathrm{s}}$ is 


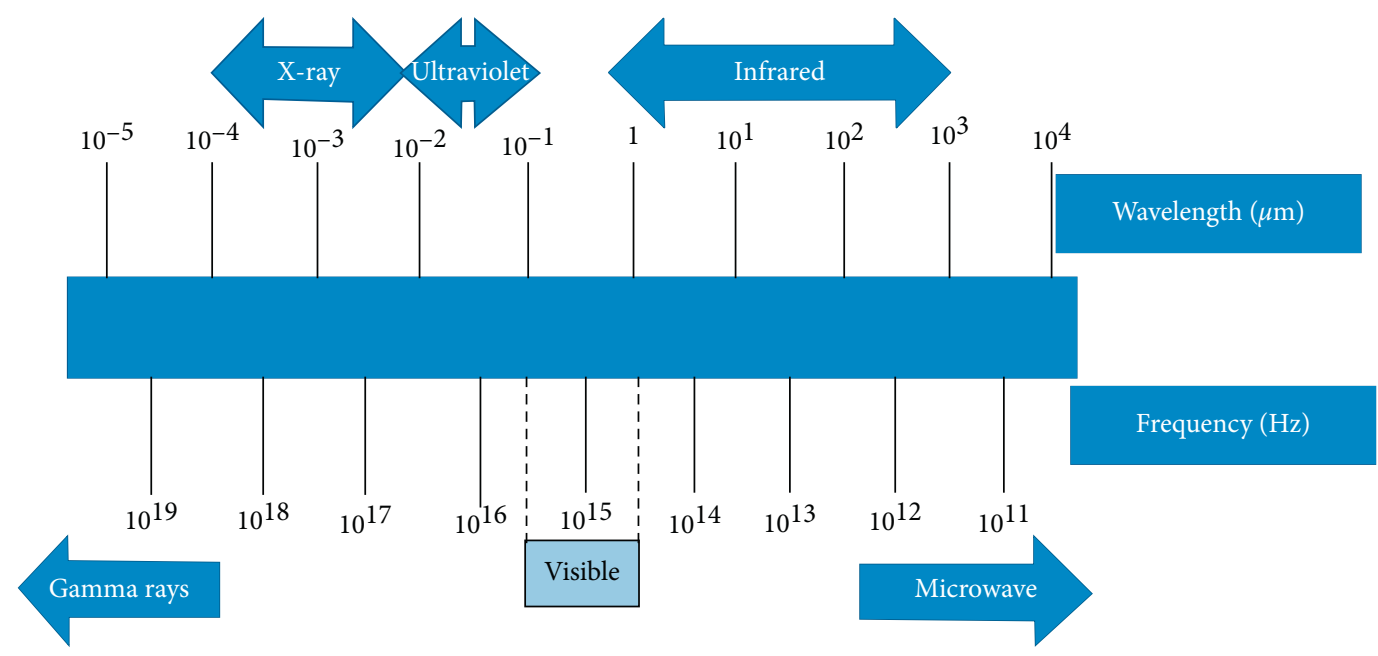

FIGURE 2: Electromagnetic radiation spectrum and wavelength range.

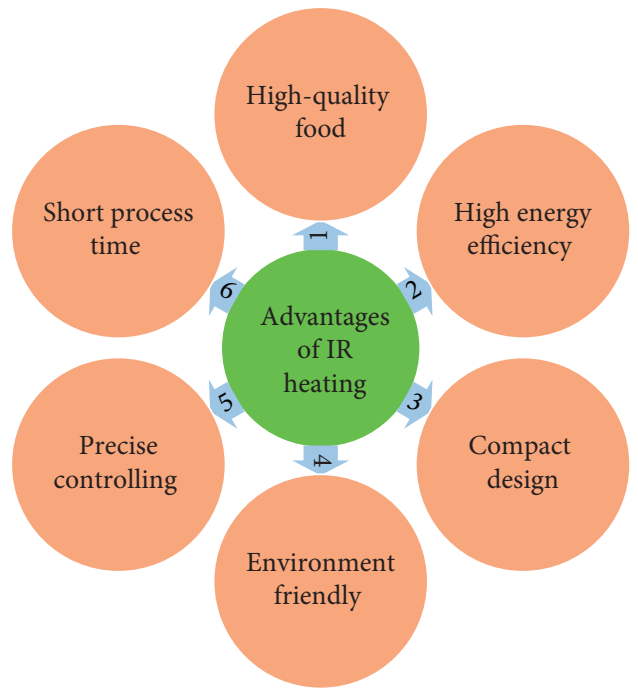

(a)

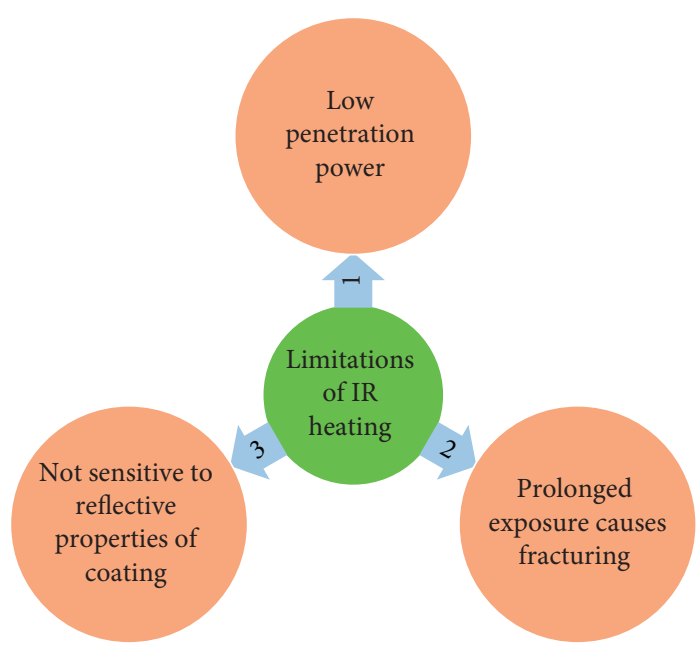

(b)

FIGURE 3: Some advantages and limitations of IR heating used for roasting nuts and other foods.

the fraction of energy between the sample surface and the wall surface.

The heat transfer coefficient, $h_{\mathrm{r}}\left(\mathrm{W} / \mathrm{m}^{2} \mathrm{~K}\right)$, is calculated using the following equation:

$$
h_{r}=\frac{q_{0}}{A_{\mathrm{IF}}\left(T_{\mathrm{IF}}-T_{\mathrm{s}}\right)} .
$$

\section{Trends and State of the Art on Infrared Roasting Technology}

Since the penetrating power of infrared rays is limited to the depth of nuts, the combination of infrared with other thermal methods such as hot air, microwave, vacuum, and other states of convection and conduction can overcome this limitation. The capability of the combination of infrared rays with other roasting methods is weighed as one of its outstanding features. Reducing roasting time and increasing roasting efficiency are advantages of combining IR with another heating method. The combination of infrared and hot air method has been extensively used for drying and roasting agricultural products, including organic blackberry [16], potato chips [35], sponge gourd slices [36], whole longans [37], pineapple rings [38], and murta berries [39]. The combination of these thermal methods intensifies the transfer of mass and heat, thus reducing the roasting time and energy consumption and increasing production efficiency $[40,41]$. However, infrared roasting is recognized to be a talented novel method; it is not suitable for roasting all nuts due to restriction of its penetrating power [42], so combining infrared and other roasting methods can be more efficient and helpful because it provides synergistic results and is considered as a currently known solution [43]. 
TABLE 1: Application of different IR roasting methods for roasting nuts and other food products.

\begin{tabular}{|c|c|c|c|}
\hline Nuts & $\begin{array}{l}\text { IR } \\
\text { type }\end{array}$ & Aims & References \\
\hline Pistachio kernel & IR & $\begin{array}{c}\text { Studying roasting optimum conditions of four Iranian commercial pistachio } \\
\text { kernels }\end{array}$ & Morshedi et al. [19] \\
\hline \multirow[b]{2}{*}{ Peanut kernel } & IR & Studying optimum conditions roasting & \multirow[b]{2}{*}{ Bagheri et al. $[20,21]$} \\
\hline & IR- & Studying quality properties and energy consumption & \\
\hline \multirow[b]{2}{*}{ Hazelnut } & IR & Monitoring quality properties of roasted hazelnuts during storage & Belviso et al. [22] \\
\hline & $\begin{array}{l}\text { IR- } \\
\text { MV }\end{array}$ & Optimizing microwave-infrared roasting & Uysal et al. [23] \\
\hline Almond & IR & Infrared heating for dry-roasting and pasteurization of almonds & Yang et al. [6] \\
\hline Wild almond & IR & Evaluating physicochemical characterization & Mokhtari \& Ziaiifar [24] \\
\hline Groundnuts & IR & Evaluating groundnuts quality & Kumar et al. [25] \\
\hline \multirow[b]{2}{*}{ Soybean snack } & IR & Modeling infrared roasting using artificial neural network (ANN) & \multirow{2}{*}{$\begin{array}{l}\text { Bagheri \& Kashaninejad } \\
{[26,27]}\end{array}$} \\
\hline & $\begin{array}{l}\text { IR- } \\
\text { HA }\end{array}$ & Investigating the kinetic modeling of mass transfer during roasting & \\
\hline $\begin{array}{l}\text { Sunflower } \\
\text { kernels }\end{array}$ & IR & $\begin{array}{l}\text { Evaluating quality characteristics and engineering of infrared-roasted sunflower } \\
\text { seed kernels by RSM }\end{array}$ & Mosayebi et al. [28] \\
\hline Rice & IR & $\begin{array}{l}\text { Designing a roasting machine using infrared rays and evaluating roasted rice } \\
\text { qualities }\end{array}$ & $\begin{array}{l}\text { Laohavanich \& Yangyuen } \\
{[29]}\end{array}$ \\
\hline Cocoa & IR & Evaluating physicochemical characterization & Rojas et al. [30] \\
\hline Sesame & IR & Evaluating formation of sesamol and quality of defatted flours & Kumar et al. [31] \\
\hline Buckwheat & IR & $\begin{array}{c}\text { Evaluating antioxidant activity, phenolic composition, and Maillard reaction } \\
\text { products }\end{array}$ & Bhinder et al. [9] \\
\hline $\begin{array}{l}\text { Black cumin } \\
\text { seed }\end{array}$ & IR & $\begin{array}{c}\text { Assessing the impact of infrared roasting on the oxidative stability and other } \\
\text { chemical properties }\end{array}$ & Suri et al. [32] \\
\hline
\end{tabular}

2.1. IR-Microwave. One of the problems associated with microwave roasting is that the surface temperature is higher than the inner parts of the food, which results in over- or under-roasted food [44]. Therefore, combining this method with other roasting methods such as infrared can be useful (Figure 4). Uysal et al. [23] studied the application of microwave-infrared method for roasting hazelnut. Their results showed that the roasting time of the hazelnuts in microwave-infrared method was deficient compared to the conventional method. The quality of roasted hazelnuts at the optimal point in terms of color, texture, moisture content, and composition of fatty acids was similar to the quality of roasted samples by conventional methods.

2.2. IR-Hot Air. The lack of uniform distribution of temperature in the product is one of the main problems of hot air thermal processes. The combination of hot air and infrared heating for roasting is much more efficient than using either of these methods alone (Figure 5). A combination of IR with hot air provides the synergistic effect, resulting in an efficient roasting process $[13,45]$. Bagheri et al. [20] combined hot air and infrared heating for roasting peanut kernels. These researchers showed that when infrared and hot air were combined for roasting peanut kernels, the energy consumption was reduced with good quality of peanut. The use of hybrid infrared radiation and hot air decreases the energy requirement by $31 \%$ compared to hot air alone.

Yang et al. [6] developed two new roasting methods for almonds: infrared roasting; sequential infrared and hot air roasting (SIRHA). Compared to traditional hot air roasting,
SIRHA heating can produce roasted almonds, with up to $30-70 \%$ reduction in processing time, and meet pasteurization requirements for producing medium degree roasted almonds at 130,140 , and $150^{\circ} \mathrm{C}$. In this study no significant difference $(P>0.05)$ was observed in sensory quality of medium roasted almonds processed with different roasting methods. They pointed out that the SIRHA roasting is a promising new method for the production of dry-roasted pasteurized almonds.

\section{Roasting of Some Nuts}

3.1. Pistachio. Pistachio is one of the most popular edible nuts in the world, which has valuable chemical and antioxidant compounds. Pistachio has high contents of nutritional compounds such as monounsaturated fatty acids, vitamins, minerals, sterols, and polyphenols [46-49]. In addition to having a pleasant taste, pistachio kernels as a functional food have been welcomed by consumers due to their significant effects on health, especially the human cardiovascular system [34].

A large percentage of pistachios are consumed as salted and roasted snacks and confections. Roasting is one of the essential processing methods which is widely used in the nut industry to improve the flavor, color, texture, and overall acceptability [1]. Four Iranian commercial pistachio kernels were roasted by Morshedi et al. [19] using an infrared roasting method. The roasting process was optimized by response surface methodology. The responses were chosen based on different aspects of quality factors: texture, color, taste, and time of roasting. The sample's first fracture point was in the range $20-40 / 5 \mathrm{~N}$, second fracture point $37-55 \mathrm{~N}$, 


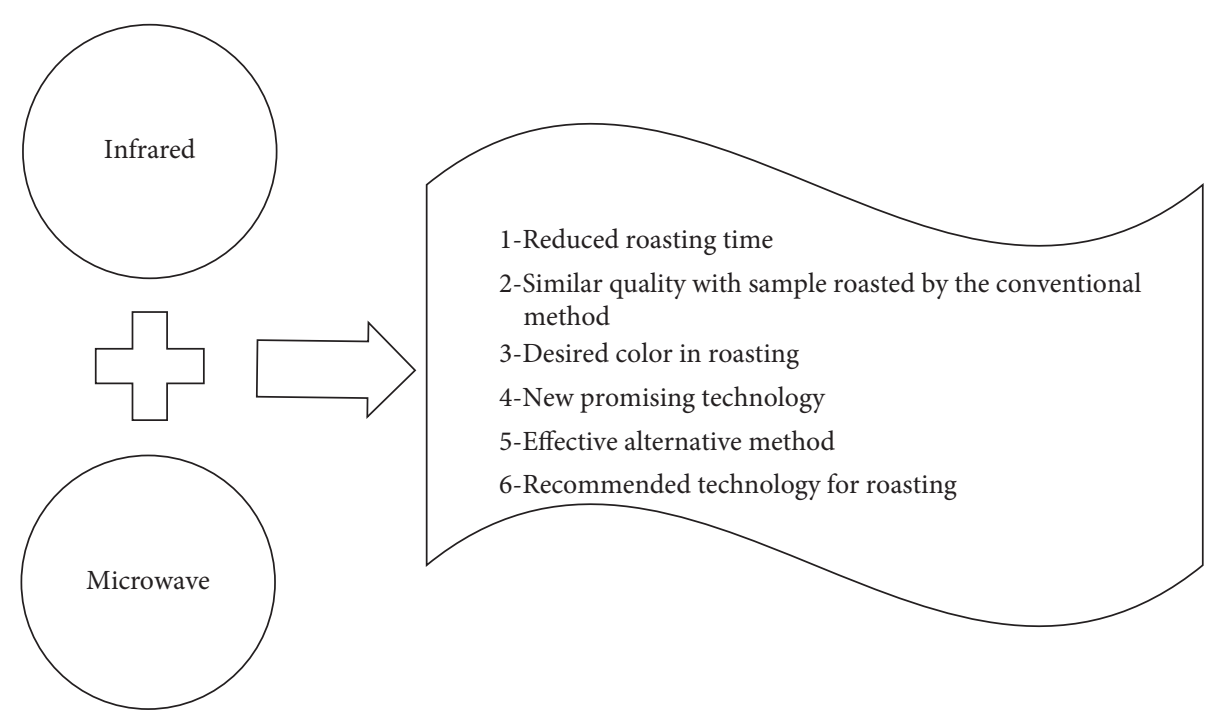

FIGURE 4: Combination of IR heating and microwave (IR-microwave) and its advantages.

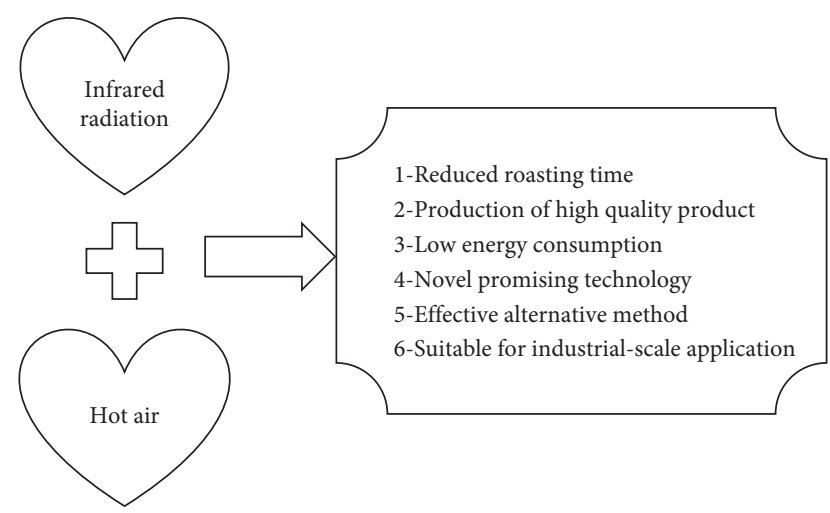

FIGURE 5: Combination of IR heating and hot air (IR-HA) and its advantages.

browning index 38-41, roasting taste score 4-9/12, and roasting time $127-746 \mathrm{~S}$, in the optimum points. A full quadratic model was fitted for responses by considering trial and error. At last, results showed that optimized points were different for every cultivar. The fitted model and experimental interventions had a good correlation $(P \leq 0.05)$. Considering final product quality, it seems that IR roasting can be a useful method for pistachio nut kernel and can reduce the processing time by at least $50 \%$.

3.2. Peanut Kernel. Peanut (Arachis hypogaea L.) is a nutritious grain that is high in protein and fat (containing $47-50 \%$ fat, $25-30 \%$ protein) and is considered an important nutrient source for humans. It belongs to the Leguminosae family [50], and it is the second harvested legume after soybeans [51]. Commonly, peanuts are known as nuts, although peanuts are legumes. Also, the peanut is known as the groundnut [50]. In addition to using peanuts for making oil, peanuts as a cheap protein source have become a snack due to their unique taste and numerous nutrients [51]. Roasting can change low-value raw materials to expensive products, and roasted peanuts are one of the valuable snack foods whose quality is directly affected by roasting [52]. Roasting peanut kernel under infrared and infrared-hot air system was studied by Bagheri et al. [20, 21]. Their study showed that, with increasing temperature, power, and time, the moisture content, solid soluble content, $\mathrm{pH}$, compressive energy, and hardness decreased and browning index, total phenolic compounds, and total acceptance of peanuts kernels increased during the roasting. After the roasting process, the hardness reduced from $91.31 \mathrm{~N}$ to $33.86 \mathrm{~N}$; also, the total color difference rose from 2.87 to 19.33 . The highest value of specific energy consumed in the roasting process was related to roasting process at $120^{\circ} \mathrm{C}$ and $130 \mathrm{~W}$ for $30 \mathrm{~min}$, and roasting at $100^{\circ} \mathrm{C}$ and $200 \mathrm{~W}$ for $10 \mathrm{~min}$ had the lowest value of compressive specific energy. A combination of infrared and hot-air-produced high-quality roasted peanuts, compared to conventional methods, had lower energy cost and shorter roasting time; therefore, it could be considered as a novel method for the peanut roasting industry.

Pulsed infrared roasting of groundnuts and its quality were studied by Kumar et al. [25]. Infrared roasting significantly reduced the roasting time as compared to other roasting methods (33\% and 60\% less compared to sand and drum roasting, respectively). In terms of color parameters, FFA, and texture, roasting at $178-188^{\circ} \mathrm{C}$ for $6.8-9.2 \mathrm{~min}$ constitutes the best conditions for roasting groundnuts. Still, in terms of sensory characteristics, the best conditions for roasting were $180^{\circ} \mathrm{C}$ and $8 \mathrm{~min}$. Infrared can be used to roast groundnuts, and pulsed infrared could be considered as a promising technique for roasting of groundnuts.

3.3. Hazelnuts. High nutritional value and bioactive compounds in hazelnut make it a valuable nutrient.

Hazelnuts are usually consumed both in a raw and roasted form and have unique taste, aroma, and crunchy texture; they are getting much attention [22]. Hazelnuts with a unique and pleasant taste are used as an ingredient in confectionery and bakery products [23]. Roasting causes 
positive changes in the organoleptic properties of hazelnuts. The use of roasted hazelnuts improves the taste of sweets, confectionery, chocolate, and biscuits [53]. Roasting also removes the hazelnut skin, reduces the moisture, and develops the desired appearance of hazelnuts [53, 54]. Also, roasting is often used to increase the shelf life of the nuts. The case occurs through the deactivation of oxidative enzymes and the formation of antioxidant products during the roasting process $[55,56]$.

The possibility of using hybridized microwave-infrared method for roasting of hazelnut was surveyed by Uysal et al. [23]. Optimal conditions for roasting hazelnuts in this system were determined as $613.8 \mathrm{~W}$ of microwave power, $900 \mathrm{~W}$ of upper halogen lamp power, and $300 \mathrm{~W}$ of lower halogen lamp power for $2.5 \mathrm{~min}$. Hazelnuts roasted at optimum conditions had comparable quality with conventionally roasted ones in terms of color, moisture content, texture, and fatty acid composition. Besides, the roasting time of the hazelnuts was significantly reduced by about $87.5 \%$. Therefore, hybridized microwave-infrared method can be considered as a promising technique for roasting of hazelnut and other nuts.

3.4. Almond Kernel. Almond (Prunus amygdalus) is a member of the Rose family and is considered a popular tree nut with essential nutrients like vitamins, minerals, and protein. Also, almonds contain relatively high levels of vitamin $\mathrm{E}$ that is beneficial for human health and nutrition [57]. Roasting is an important step in nuts processing and one of the ways to improve the color, flavor, and unique aroma and taste. The use of infrared heating in combination with hot air for roasting and safety of almonds was investigated by Yang et al. [6]. The result showed that sequential infrared and hot air (SIRHA) roasting is preferable to infrared and hot air roasting methods. This advantage of SIRHA was due to reduced roasting time and pasteurization of almond kernels. Therefore, SIRHA roasting is an excellent method for the production of dry-roasted pasteurized almonds.

3.5. Sunflower Seeds. The sunflower seed is the fruit of the sunflower (Helianthus annuus L.) [58]. Sunflower seeds contain several nutrients such as unsaturated fatty acids, proteins, fiber, vitamins, and minerals. The use of sunflower seeds for snack food is important for nutritional reasons, and it is used in combination with other nuts or alone [59]. Roasting is the typical shape of sunflower seed processing, and the purpose is to increase the total acceptability of the product [28]. The effect of infrared (IR) power (400-600 W) and roasting time (4-10 $\mathrm{min}$ ) on energy consumption, color parameters $\left(L^{*}, a^{*}\right.$, and $b^{*}$ values, $\left.\Delta \mathrm{E}, \mathrm{BI}, \mathrm{SI}, \mathrm{WI}, h^{\circ}\right)$, texture, moisture content, and sensory properties of sunflower kernel was investigated by Mosayebi et al. [28]. Also, the regression models for the responses were obtained, and the proper roasting conditions were determined using response surface methodology (RSM). A quadratic model was proposed for color change $\left(L^{*}, a^{*}, \Delta \mathrm{E}, h^{\circ}, \mathrm{WI}\right)$ and linear relation for texture, BI, and moisture content and $2 \mathrm{FI}$ for energy consumption. Roasting at $492.5 \mathrm{~W}$ IR power for 9.1 min was found to be suitable for proper roasting conditions. Also, roasted kernels had acceptable quality in terms of sensory properties compared to the conventional method (hot air).

3.6. Wild Almond Kernel. Wild almond kernel (Amygdalus Dulcis) could be used as edible nutritive oil and kernel [44]. Almonds can be used as a snack food and as an ingredient in a wide range of processed foods, especially in bakery and confectionery $[60,61]$. Besides, almonds have application in the antidiabetic, anti-inflammation, antibacterial, and laxative agent [62]. Roasting is one of the critical processing methods widely used in the nut industry to improve the flavor, color, texture, and overall acceptability. The infrared roasting was applied to roast wild almond kernels by Mokhtari and Ziaiifar [24]. Effect of processing conditions including infrared power $(200 \mathrm{~W}, 300 \mathrm{~W})$ during roasting $(15,25$, and $35 \mathrm{~min})$ on moisture content, chemical properties, color, and sensory properties was investigated. The results showed that increasing the infrared power and roasting time decreased $\mathrm{pH}$ and moisture content. Finally, infrared with power of $200 \mathrm{~W}$ for $15 \mathrm{~min}$ was the recommendable processes for wild almond roasting.

3.7. Soybean. Soybean is recognized as a healthy food because it is an excellent source of essential nutrients, including proteins, fat, and some active compounds, and is obtaining increased notice due to its low cost and high nutritious value [63]. Although soybean has been used for human consumption in some countries in Asia, there is a limitation to its use in other parts of the world. Raw soybeans have a beany, bitter, and astringent flavor, which has been the most significant factor limiting the utilization of this product. Hence to raise its consumption, the specific flavor of raw soybean must be eliminated. Roasting is one of the methods for this purpose [26]. Roasting creates a pleasant flavor without any beany odor or bitter taste [27] and significantly enhances the flavor, color, texture, and appearance of the beans and nuts [64]. The roasted product is delicate, uniquely nutty, and widely enjoyed as compared to the raw bean. Roasting also removes the bitter taste of soybean, inactivates the enzymes, and destroys unwelcome microorganisms and food pollution [26]; therefore, roasted soybean has the potential to be used as snacks. Bagheri and Kashaninejad [27] developed new roasting methods for roasting of soybeans. In this research, the kinetics and modeling of soybean roasting using combined infrared-hot air system and consumption of energy were investigated. The results showed that the effect of hot air temperature, infrared power, and combined hot air temperature and IR power on the roasting rate of soybean was statistically significant and the roasting process occurred within the falling rate period. Among the five thin-layer roasting models fitted to the experimental data, the page model was the best to describe the roasting behavior. Comparison of roasting methods showed that minimum energy was consumed in the infrared process $(0.0905 \mathrm{kWh})$ and maximum energy was recorded 
for hot air roasting $(1.752 \mathrm{kWh})$; thus, infrared heating could be considered proper technique for roasting of soybeans for removing bitter taste of soybean and increasing its acceptance rate.

\section{Roasting Other Food Products}

4.1. Cocoa. Cocoa beans contain many more polyphenolic compounds (flavonoids). Using this crop improves cardiovascular health and helps balance cholesterol in the body [64]. Antiallergic, anti-inflammatory, antiviral, and anticarcinogenic properties are other flavonoid advantages $[65,66]$. The most critical operation for processing cocoa beans is roasting, and the amount of chemical changes depends on the temperature and time applied during the process. Roasting modifies the precursor compounds of flavor and aromas of origin, those formed during fermentation and drying (postharvest treatment). Also, during roasting, unwanted volatile acids are removed, desired flavor components are assembled by Maillard reaction, water content of cocoa is reduced, and color of cocoa darkens [2]. Also, the heat treatment caused the generation of pyrazines, which gives it a sweet taste and a chocolate aroma.

Physicochemical characterization of cocoa (Theobroma cacao L.) during infrared roasting was studied by Rojas et al. [30]. The heating process caused a decrease in the surface area, as well as the pore radius due to the melting and movement of fats inside of structure resulting in a more compact material in roasted cocoa. Heat treatment caused the generation of pyrazines, which gives it a sweet taste and a chocolate aroma. Tetramethyl pyrazine is the most relevant, which presents its highest concentration when roasted at $150^{\circ} \mathrm{C}$; that is, if $200^{\circ} \mathrm{C}$ is used, it is probably volatilizing with higher speed due to the high temperature; therefore, when analyzing the material, roasted solid was found in a smaller amount.

4.2. Buckwheat. Buckwheat belongs to the Polygonaceae family, and it is a drought-tolerant crop. Buckwheat is a pseudocereal crop that is gaining amicability due to its unique nutritional properties [67]. Buckwheat has numerous nutritional benefits (high flavonoid content). Still, its crop contains potential allergens like protein inhibitors and toxins, such as fagopyrin, that are harmful to human health [9]. Roasting can potentially reduce these harmful components. In addition, roasting enhances the flavor, shelf life, and crispness as compared to its raw sample. Effect of infrared roasting on the physicochemical properties of buckwheat varieties was investigated by Bhinder et al. [9]. Roasting is a good method to improve flavor and inactivate antinutritional components present in buckwheat. The optimization of roasting time and temperature combination helps to increase the consumption of this crop. The best condition for roasting buckwheat was $130^{\circ} \mathrm{C}$ for $10 \mathrm{~min}$ due to the high amount of preserved nutrients.

4.3. Chili Pepper. Chili pepper (Capsicum annuum L.) is one of the most widely cultivated peppers in the world. Chili red pepper is an excellent source of vitamins $\mathrm{A}$ and $\mathrm{C}$ and is rich in beta-carotene and minerals such as potassium [68]. Commonly electrically heated mechanical roasters are used for roasting chili pepper. The effect of roasting with far-infrared heating on quality of chili was studied by Fernando et al. [69]. The results showed that FIR radiation could be used to roast chili peppers. Also, the results indicated that processing time was significantly reduced. About 25 minutes is needed to roast chili with the drum roaster, but roasting chili with similar color and moisture content using infrared with a radiation intensity of $7188 \mathrm{~W} / \mathrm{m}^{2}$ takes about 60 seconds. Therefore, FIR radiation can be used to roast chili with acceptable quality characteristics.

4.4. Roasted Rice. Roasted rice is simply white rice that has been dry-roasted until the grains turn a rich brown color. Roasted rice is a product made from rice or sticky rice. To produce roasted rice, first, the rice grain is washed and soaked in water for several hours. Then the soaked rice is roasted in a hot pan until it is crunchy. Roasted rice is the primary material for preparing Larb Gai (spicy ground chicken), a delicious dish served throughout Thailand, and is becoming very popular in Thai restaurants around the world. The effect of infrared roasting machine at $750-800^{\circ} \mathrm{C}$ and drum speed of 5-7 rpm on rice quality was examined by Laohavanich \& Yangyuen [29]. Roasting at $800^{\circ} \mathrm{C}$ for $9.1 \mathrm{~min}$, drum speed of $6 \mathrm{rpm}$, and roasting time of 40 minutes were found to be suitable roasting conditions. Also, it had acceptable quality in terms of sensory properties compared to other roasted rice in the market.

\section{Conclusion and Future Prospective of IR Roasting}

Roasting is an essential process that improves the taste, color, texture, and appearance of products. Based on studies done, infrared can be introduced as a replacement of the conventional methods for roasting nuts and other foods. Compared with other common roasting methods, IR roasting offers many advantages such as high-quality product, greater energy saving and efficiency, and higher heat transfer rate and heat flux, which results in decreased drying time and higher roasting rate. IR effectiveness is between $80 \%$ and $90 \%$, the produced radiation is in narrow wavelength range, and they are miniaturized. The effect of IR roasting on physicochemical properties, sensory properties, and nutritional values of nuts as well as the interaction of components under IR radiation may further justify the use of IR radiation as a future novel roasting option. The interaction between processes and products needs coherent experiments in order to gain more knowledge.

\section{Data Availability}

The data used to support the findings of this study are available from the author upon request.

\section{Conflicts of Interest}

The author declares that there are no conflicts of interest regarding the publication of this paper. 


\section{Acknowledgments}

The author would like to thank the Gorgan University of Agricultural Sciences and Natural Resources.

\section{References}

[1] A. Goszkiewicz, E. Kołodziejczyk, and F. Ratajczyk, "Comparison of microwave and convection method of roasting sunflower seeds and its effect on sensory quality, texture and physicochemical characteristics," Food Structure, vol. 25, Article ID 100144, 2020.

[2] E. O. Afoakwa, Chocolate Science and Technology, John Wiley \& Sons, Hoboken, NJ, USA, 2016.

[3] J. Roche, M. Alignan, A.. Bouniols, M. Cerny, Z. Mouloungui, and O. Merah, "Sterol concentration and distribution in sunflower seeds (Helianthus annuus L.) during seed development," Food Chemistry, vol. 119, no. 4, pp. 1451-1456, 2010.

[4] S. Guo, K. N. Jom, and Y. Ge, "Influence of roasting condition on flavor profile of sunflower seeds: a flavoromics approach," Scientific Reports, vol. 9, no. 1, pp. 1-10, 2019.

[5] S. Kavitha and R. Parimalavalli, "Effect of processing methods on proximate composition of cereal and legume flours," Journal of Human Nutrition and Food Science, vol. 2, no. 4, p. 1051, 2014.

[6] J. Yang, G. Bingol, Z. Pan, M. T. Brandl, T. H. McHugh, and H. Wang, "Infrared heating for dry-roasting and pasteurization of almonds," Journal of Food Engineering, vol. 101, no. 3, pp. 273-280, 2010.

[7] A. Agila and S. Barringer, "Effect of roasting conditions on color and volatile profile including HMF level in sweet almonds (Prunus dulcis)," Journal of Food Science, vol. 77, no. 4, pp. 461-468, 2012.

[8] N. Allanic, P. Le Bideau, P. Glouannec, and R. Deterre, "An experimental study on infrared drying kinetics of an aqueous adhesive supported by polymer composite," Heat and Mass Transfer, vol. 53, no. 1, pp. 223-231, 2016.

[9] S. Bhinder, B. Singh, A. Kaur et al., "Effect of infrared roasting on antioxidant activity, phenolic composition and Maillard reaction products of Tartary buckwheat varieties," Food Chemistry, vol. 285, pp. 240-251, 2019.

[10] L. Wang, M. Zhang, Z. Fang, and B. Xu, “Application of intermediate-wave infrared drying in preparation of mushroom chewing tablets," Drying Technology, vol. 32, no. 15, pp. 1820-1827, 2014.

[11] M. Zhou, C. Li, J. Bi, X. Jin, J. Lyu, and X. Li, "Towards understanding the enhancement of moisture diffusion during intermediate-infrared drying of peach pomace based on the glass transition theory," Innovative Food Science \& Emerging Technologies, vol. 54, pp. 143-151, 2019.

[12] R. Sadin, G.-R. Chegini, and H. Sadin, "The effect of temperature and slice thickness on drying kinetics tomato in the infrared dryer," Heat and Mass Transfer, vol. 50, no. 4, pp. 501-507, 2014.

[13] Y. Mazaheri, M. Torbati, S. Azadmard-Damirchi, and G. P. Savage, "Effect of roasting and microwave pre-treatments of Nigella sativa L. seeds on lipase activity and the quality of the oil," Food Chemistry, vol. 274, pp. 480-486, 2019.

[14] M. H. Riadh, S. A. B. Ahmad, M. H. Marhaban, and A. C. Soh, "Infrared heating in food drying: an overview," Drying Technology, vol. 33, no. 3, pp. 322-335, 2015.

[15] Y.-X. Wen, L.-Y. Chen, B.-S. Li, Z. Ruan, and Q. Pan, "Effect of infrared radiation-hot air (IR-HA) drying on kinetics and quality changes of star anise (Illicium verum)," Drying Technology, pp. 1-14, 2020.

[16] E. Taghinezhad, M. Kaveh, E. Khalife, and G. Chen, "Drying of organic blackberry in combined hot air-infrared dryer with ultrasound pretreatment," Drying Technology, pp. 1-17, 2020.

[17] B. Wu, Z. Pan, W. Qu, B. Wang, J. Wang, and H. Ma, "Effect of simultaneous infrared dry-blanching and dehydration on quality characteristics of carrot slices," LWT-Food Science and Technology, vol. 57, no. 1, pp. 90-98, 2014.

[18] R. Sadin, G. R. Chegini, and M. Khodadadi, "Development and performance evaluation of a combined infrared and hot air dryer," Journal of Biological and Environmental Sciences, vol. 8, no. 22, pp. 11-18, 2014.

[19] A. Morshedi, S. Razavi, M. Kashaninejad, A. Shaker Ardakani, and A. Mostafavi, "Important Iranian pistachio kernel cultivars infrared roasting optimization by RSM," Innovative Food Technologies, vol. 6, no. 1, pp. 121-136, 2018.

[20] H. Bagheri, M. Kashaninejad, A. M. Ziaiifar, and M. Aalami, "Novel hybridized infrared-hot air method for roasting of peanut kernels," Innovative Food Science \& Emerging Technologies, vol. 37, pp. 106-114, 2016.

[21] H. Bagheri, M. Kashaninejad, A. M. Ziaiifar, and M. Aalami, "Textural, color and sensory attributes of peanut kernels as affected by infrared roasting method," Information Processing in Agriculture, vol. 6, no. 2, pp. 255-264, 2019.

[22] S. Belviso, B. Dal Bello, S. Giacosa et al., "Chemical, mechanical and sensory monitoring of hot air- and infraredroasted hazelnuts (Corylus avellana L.) during nine months of storage," Food Chemistry, vol. 217, pp. 398-408, 2017.

[23] N. Uysal, G. Sumnu, and S. Sahin, "Optimization of microwave-infrared roasting of hazelnut," Journal of Food Engineering, vol. 90, no. 2, pp. 255-261, 2009.

[24] Z. Mokhtari and A. Ziaiifar, "The effect of different methods of roasting on the physico chemical properties of wild almond," Innovative Food Technologies, vol. 6, no. 1, pp. 55-73, 2018.

[25] S. Kumar, S. Debnath, and U. H. Hebbar, "Pulsed infrared roasting of groundnuts and its quality," International Journal of Food Engineering, vol. 5, no. 4, $2009 \mathrm{~b}$.

[26] H. Bagheri and M. Kashaninejad, "Kinetic modeling of mass transfer during roasting of soybeans using combined infraredhot air heating," Journal of Food Biosciences and Technology, vol. 8, no. 1, pp. 1-12, 2018.

[27] H. Bagheri and M. Kashaninejad, "Modeling of soybean snack roasting by infrared heating using artificial neural network (ANN)," Journal of Food Technology and Nutrition, vol. 15, no. 4, pp. 19-30, 2018.

[28] M. Mosayebi, M. Kashaninejad, and L. Najafian, "Evaluation of quality characteristics and engineering of infrared-roasted sunflower seeds kernels by RSM," Food Science and Technology, vol. 16, no. 88, pp. 271-287, 2019.

[29] J. Laohavanich and S. Yangyuen, "Rice roasting machine using infrared ray," in Proceedings of the 2018 Third International Conference on Engineering Science and Innovative Technology (ESIT), pp. 1-5, IEEE, North Bangkok, Thailand, April 2018.

[30] M. Rojas, C. Farid, C. Hector, and M. Jorge, "Physicochemical characterization of cocoa (theobroma cacao L) during infrared roasting process," Xii Cibia Iberoamercan Congress of Food Engineering, Challenging Food Engineering as a Driver towards Sustainable Food Processing, Universidade do Algarve, Faro, Portugal, 2019.

[31] C. M. Kumar, A. G. A. Rao, and S. A. Singh, "Effect of Infrared heating on the formation of sesamol and quality of defatted 
flours from sesamum indicum L," Journal of Food Science, vol. 74, no. 4, pp. 105-111, 2009.

[32] K. Suri, B. Singh, A. Kaur, M. P. Yadav, and N. Singh, "Impact of infrared and dry air roasting on the oxidative stability, fatty acid composition, Maillard reaction products and other chemical properties of black cumin (Nigella sativa L.) seed oil," Food Chemistry, vol. 295, pp. 537-547, 2019.

[33] D. I. Onwude, N. Hashim, K. Abdan, R. Janius, and G. Chen, "Modelling the mid-infrared drying of sweet potato: kinetics, mass and heat transfer parameters, and energy consumption," Heat and Mass Transfer, vol. 54, no. 10, pp. 2917-2933, 2018.

[34] B. L. Halvorsen, M. H. Carlsen, K. M. Phillips et al., "Content of redox-active compounds (ie, antioxidants) in foods consumed in the United States," The American Journal of Clinical Nutrition, vol. 84, no. 1, pp. 95-135, 2006.

[35] N. Supmoon and A. Noomhorm, "Influence of combined hot air impingement and infrared drying on drying kinetics and physical properties of potato chips," Drying Technology, vol. 31, no. 1, pp. 24-31, 2013.

[36] Y. Zhang, G. Zhu, X. Li et al., "Combined medium- and shortwave infrared and hot air impingement drying of sponge gourd (Luffa cylindrical) slices," Journal of Food Engineering, vol. 284, Article ID 110043, 2020.

[37] P. Nuthong, A. Achariyaviriya, K. Namsanguan, and S. Achariyaviriya, "Kinetics and modeling of whole longan with combined infrared and hot air," Journal of Food Engineering, vol. 102, no. 3, pp. 233-239, 2011.

[38] K. Ponkham, N. Meeso, S. Soponronnarit, and S. Siriamornpun, "Modeling of combined far-infrared radiation and air drying of a ring shaped-pineapple with/without shrinkage," Food and Bioproducts Processing, vol. 90, no. 2, pp. 155-164, 2012.

[39] L. Puent-Diaz, K. Ah-Hen, A. Vega-Galvez, R. LemusMondaca, and K. Scala, "Combined infrared-convective drying of murta (UgnimolinaeTurcz) berries: kinetic modeling and quality assessment," Drying Technology, vol. 31, pp. 329-338, 2013.

[40] S. Jaturonglumlert and T. Kiatsiriroat, "Heat and mass transfer in combined convective and far-infrared drying of fruit leather," Journal of Food Engineering, vol. 100, no. 2, pp. 254-260, 2010.

[41] S. Siriamornpun, O. Kaisoon, and N. Meeso, "Changes in colour, antioxidant activities and carotenoids (lycopene, $\beta$-carotene, lutein) of marigold flower (Tagetes erecta L.) resulting from different drying processes," Journal of Functional Foods, vol. 4, no. 4, pp. 757-766, 2012.

[42] Y. Pei, Z. Li, C. Song et al., "Effects of combined infrared and hot-air drying on ginsenosides and sensory properties of ginseng root slices (Panax ginseng Meyer)," Journal of Food Processing and Preservation, vol. 44, no. 1, Article ID e14312, 2020.

[43] S. Asadi, M. Aalami, S. Shoeibi, M. Kashaninejad, M. Ghorbani, and M. Delavar, "Effects of different roasting methods on formation of acrylamide in pistachio," Food Science \& Nutrition, vol. 8, no. 6, pp. 2875-2881, 2020.

[44] M. Hojjati, L. Lipan, and Á. A. Carbonell-Barrachina, "Effect of roasting on physicochemical properties of wild almonds (Amygdalus scoparia)," Journal of the American Oil Chemists' Society, vol. 93, no. 9, pp. 1211-1220, 2016.

[45] A. Nawirska, A. Figiel, A. Z. Kucharska, A. Sokół-Łętowska, and A. Biesiada, "Drying kinetics and quality parameters of pumpkin slices dehydrated using different methods," Journal of Food Engineering, vol. 94, no. 1, pp. 14-20, 2009.

[46] S. K. Gebauer, S. G. West, C. D. Kay, P. Alaupovic, D. Bagshaw, and P. M. Kris-Etherton, "Effects of pistachios on cardiovascular disease risk factors and potential mechanisms of action: a dose-response study," The American Journal of Clinical Nutrition, vol. 88, no. 3, pp. 651-659, 2008.

[47] C. D. Kay, S. K. Gebauer, S. G. West, and P. M. Kris-Etherton, "Pistachios increase serum antioxidants and lower serum oxidized-LDL in hypercholesterolemic adults," The Journal of Nutrition, vol. 140, no. 6, pp. 1093-1098, 2010.

[48] Z. Li, R. Song, C. Nguyen et al., "Pistachio nuts reduce triglycerides and body weight by comparison to refined carbohydrate snack in obese subjects on a 12-week weight loss program," Journal of the American College of Nutrition, vol. 29, no. 3, pp. 198-203, 2010.

[49] A. Tomaino, M. Martorana, T. Arcoraci, D. Monteleone, C. Giovinazzo, and A. Saija, "Antioxidant activity and phenolic profile of pistachio (Pistacia vera L., variety Bronte) seeds and skins," Biochimie, vol. 92, no. 9, pp. 1115-1122, 2010.

[50] R. Floriano, K. Grabin, R. C. Rossi, C. D. Ferreira, and V. Ziegler, "Impact of roasting conditions on the quality and acceptance of the peanut paste," Journal of Texture Studies, 2020.

[51] S. Jiao, D. Zhu, Y. Deng, and Y. Zhao, "Effects of hot airassisted radio frequency heating on quality and shelf-life of roasted peanuts," Food and Bioprocess Technology, vol. 9, no. 2, pp. 308-319, 2015.

[52] T. Chen, B. Kang, S. Chen, H. Chen, and H. Lin, "Optimized parameters and quality analysis of salty and crisp peanut by far infrared roasting," Transactions of the Chinese Society of Agricultural Engineering, vol. 26, no. 8, pp. 320-325, 2010.

[53] A. D. Demir and K. Cronin, "Modelling the kinetics of textural changes in hazelnuts during roasting," Simulation Modelling Practice and Theory, vol. 13, no. 2, pp. 97-107, 2005.

[54] M. Özdemir, F. Açkurt, M. Yildiz, G. Biringen, T. Gürcan, and M. Löker, "Effect of roasting on some nutrients of hazelnuts (Corylus Avellena L.)," Food Chemistry, vol. 73, no. 2, pp. 185-190, 2001.

[55] U. Krings and R. G. Berger, "Antioxidant activity of some roasted foods," Food Chemistry, vol. 72, no. 2, pp. 223-229, 2001.

[56] R. Perren and F. Escher, "Nut roasting technology and product quality," The Manufacturing Confectioner, vol. 87, pp. 65-75, 2007.

[57] A. N. Carey, S. M. Poulose, and B. Shukitt-Hale, "The beneficial effects of tree nuts on the aging brain," Nutrition and Aging, vol. 1, no. 1, pp. 55-67, 2012.

[58] C. W. Wrigley, H. Corke, K. Seetharaman, and J. Faubion, Encyclopedia of Food Grains, Academic Press, Cambridge, MA, USA, 2015.

[59] V. R. Preedy and R. R. Watson, Nuts and Seeds in Health and Disease Prevention, Academic Press, Cambridge, MA, USA, 2020.

[60] L. Xiao, J. Lee, G. Zhang et al., "HS-SPME GC/MS characterization of volatiles in raw and dry-roasted almonds (Prunus dulcis)," Food Chemistry, vol. 151, pp. 31-39, 2014.

[61] A. Agila and S. Barringer, "Effect of roasting conditions on color and volatile profile including HMF level in sweet almonds (Prunus dulcis)," Journal of Food Science, vol. 77, no. 4, pp. C461-C468, 2012.

[62] A. Kermanshah, P. Ziarati, J. Asgarpanah, and M. Qomi, "Food values of two endemic wild almond species from Iran," International Journal of Plant, Animal and Environmental Sciences, vol. 4, no. 3, pp. 380-388, 2014.

[63] S. Dondee, N. Meeso, S. Soponronnarit, and S. Siriamornpun, "Reducing cracking and breakage of soybean grains under 
combined near-infrared radiation and fluidized-bed drying," Journal of Food Engineering, vol. 104, no. 1, pp. 6-13, 2011.

[64] I. S. Rocha, L. R. R. D. Santana, S. E. Soares, and E. D. S. Bispo, "Effect of the roasting temperature and time of cocoa beans on the sensory characteristics and acceptability of chocolate," Food Science and Technology, vol. 37, no. 4, pp. 522-530, 2017.

[65] A. Othman, A. Ismail, N. A. Ghani, and I. Adenan, "Antioxidant capacity and phenolic content of cocoa beans," Journal of Food Chemistry, vol. 100, no. 1, pp. 1523-1530, 2007.

[66] L. H. Yao, Y. M. Jiang, J. Shi et al., "Flavonoids in food and their health benefits," Plant Foods for Human Nutrition, vol. 59, no. 1, pp. 113-122, 2004.

[67] M. Zhang, H. Chen, J. Li, Y. Pei, and Y. Liang, "Antioxidant properties of tartary buckwheat extracts as affected by different thermal processing methods," LWT-Food Science and Technology, vol. 43, no. 1, pp. 181-185, 2010.

[68] M. A. Hossain, J. L. Woods, and B. K. Bala, "Simulation of solar drying of chilli in solar tunnel drier," International Journal of Sustainable Energy, vol. 24, no. 3, pp. 143-153, 2005.

[69] A. J. Fernando, K. S. P. Amaratunga, L. B. M. D. L. Priyadarshana, D. D. K. Galahitiyawa, and K. G. W. U. Karunasinghe, "Roasting chilli (Capsicum Annum L.) using far-inrared radiation," Tropical Agricultural Research, vol. 25, no. 2, p. 180, 2014. 